\title{
Associations between dengue and combinations of weather factors in a city in the Brazilian Amazon
}

\author{
Maria Goreti Rosa-Freitas, ${ }^{1,4}$ Kathleen V. Schreiber, ${ }^{2}$ Pantelis Tsouris, ${ }^{3,4}$ \\ Ellem Tatiani de Souza Weimann, ${ }^{3}$ and José Francisco Luitgards-Moura ${ }^{3}$
}

Suggested citation Rosa-Freitas MG, Schreiber KV, Tsouris P, Weimann ETDS, Luitgards-Moura JF. Associations between dengue and combinations of weather factors in a city in the Brazilian Amazon. Rev Panam Salud Publica. 2006;20(4):256-67.

ABSTRACT Objectives. Dengue has become the most important endemic disease in Brazil. The Amazonian state of Roraima has one of the highest incidence rates of dengue in the country. The objective of this study was to determine whether significant temporal relationships exist between the number of reported dengue cases and short-term climate measures for the city of Boa Vista, the capital of Roraima. If such relationships exist, that suggests that it may be possible to predict dengue case numbers based on antecedent climate, thus helping develop a climatebased dengue early-warning system for Boa Vista.

Methods. Seasonal Pearson product-moment correlations were developed between 3-week running averages of daily numbers of reported dengue cases for September 1998-December 2001 and certain meteorological variables (thermal, hydroclimatic, wind, atmospheric pressure, and humidity) up to 25 weeks before. Two-sample $\mathrm{t}$ tests were also applied to test for statistically significant differences between samples of daily dengue cases with above-average values and samples with below-average values for three-variable meteorological combinations. These multivariate combinations consisted of the three climate measures that together explained the greatest portion of the variance in the number of dengue cases for the particular season.

Results. The strength of the individual averaged correlations varied from weak to moderate. The correlations differed according to the period of the year, the particular climatic variable, and the lag period between the climate indicator and the number of dengue cases. The seasonal correlations in our study showed far stronger relationships than had daily, full-year measures reported in previous studies. Two-sample $\mathrm{t}$ tests of multivariate meteorological combinations of atmospheric pressure, wind, and humidity values showed statistically significant differences in the number of reported dengue cases.

Conclusions. Relationships between climate and dengue are best analyzed for short, relevant time periods. Climate-based multivariate temporal stochastic analyses have the potential to identify periods of elevated dengue incidence, and they should be integrated into local control programs for vector-transmitted diseases.

Key words Dengue; disease outbreaks; Aedes; climate; weather; models, biological; forecasting; Brazil.

Instituto Oswaldo Cruz, Departamento de Entomologia, Laboratório de Transmissores de Hematozoários, Rio de Janeiro, Rio de Janeiro, Brasil. Send correspondence to: Maria Goreti Rosa-Freitas, Departamento de Entomologia, Instituto Oswaldo Cruz, Av. Brasil 4365, Manguinhos, 21045-900, Rio de Janeiro, RJ, Brasil; telephone: (21) 2598-4320 x21; fax: (21) 2573-4468; e-mail: maria@freitas-tsouris. com

2 Millersville University of Pennsylvania, Department of Geography, Millersville, Pennsylvania, United States of America.
3 Universidade Federal de Roraima, Centro de Ciências Biológicas e da Saúde, Núcleo Avançado de Vetores, Convênio Fundação Oswaldo CruzUniversidade Federal de Roraima, Boa Vista, Roraima, Brasil.

4 Freitas-Tsouris Consultants, Spata, Attica, Greece. 
The term "tropical disease" itself implies relationships between climate and disease. Climate alone cannot explain all natural history of arthropodborne diseases (1). Nonetheless, climate is an important component of spatial and temporal distributions of vector-borne disease, acting both to limit its spread and influence transmission dynamics. When properly assessed, climate variables may improve our understanding of seasonality and our prediction of epidemics.

The municipality of Boa Vista is the capital of the state of Roraima, which is located in the northern part of Brazil, on the border with Guyana and Venezuela. Previous analyses assessing climatic relationships with dengue for Boa Vista have shown only mild correlations between meteorological variables and the number of dengue cases (2). Work conducted elsewhere (2-5) has shown clearer evidence of the existence of dengue seasonality associated with meteorology. Similarly, statistically significant correlations between past El Niño Southern Oscillation events and epidemic dengue for Indonesia and northern South America have been found (6). In related work for malaria, a detrended time series of malaria incidence in Madagascar (1972-1989) indicated that minimum temperature during two months at the start of the transmission season could account for most of the variability between years $\left(r^{2}=0.66\right)(7)$. This finding highlights the importance of identifying relevant parameters during critical periods of the transmission season in order to aid epidemic forecasting and to assess the potential impact of global warming (7).

Temporal changes in the vector's environment brought on by climate variability and change are driven mostly by meteorological variables that greatly impact the relationship among hosts, parasites, and vectors $(8,9)$. For dengue, higher ambient temperatures shorten the extrinsic incubation period (EIP) (10) and increase the biting rate (11), while increasing mosquito survival (12-14) and, therefore, vectorial capacity and transmission (1). Because more mosquitoes would sur- vive the shortened EIP, greater dengue transmission would result. Rising humidity has also been found to increase adult mosquito survival and fecundity $(15,16)$. Dengue and its more severe forms, dengue hemorrhagic fever and dengue shock syndrome, are usually high during and after the rainy season, when temperature ranges and humidity favor dengue transmission. Increases in the numbers of dengue cases during and after the rainy season have been observed in Brazil (17), India (3), and Thailand (4). However, dengue relationships with meteorological variables may be obscured by the synanthropic nature of the vector. Domiciliary and peridomiciliary areas can provide a variety of suitable breeding places, each with distinct temperature and humidity niches $(18,19)$.

The purpose of this study was to examine temporal relationships between the number of reported dengue cases for 1999-2001 in Boa Vista and meteorological factors and their combinations in relation to their potential for predicting future temporal variations in the numbers of dengue cases. An earlier analysis of ours assessed climatic relationships with dengue for Boa Vista (2), and it showed only mild correlations between daily meteorological variables and the number of dengue cases. Work conducted elsewhere $(5,7)$ has shown clearer evidence of the existence of climate/dengue relationships. This paper reevaluates links between climate and the number of dengue cases for Boa Vista, using more powerful statistical tools than used in our previous analysis.

Identification of associations between particular (combinations of) weather factors and the number of dengue cases is significant because such findings may provide the foundation for development of a climate-based dengue early warning system. Such systems attempt to avert epidemic morbidity and mortality through identification of periods in which climate results in ensuing peak numbers of dengue cases. A warning can then be generated that allows effective timing of emergency vector control procedures and targeting. Climate-based stochastic prediction is advantageous in that it is based on low-cost, widely available weather data that may prove useful in determining the most effective time for community-based human behavior change efforts and also implementing intervention/control programs.

\section{MATERIALS AND METHODS}

\section{Place of study}

The state of Roraima is located in the Amazon region of Brazil (Figure 1). The city of Boa Vista is the capital of Roraima. Within Brazil, dengue was first diagnosed and isolated from human hosts and mosquito vectors in Boa Vista (20-22). This occurred during an outbreak there in 1981-1982, with 12000 dengue cases and an incidence rate that reached 1160 per 10000 inhabitants.

Dengue now occurs in all of Brazil's 27 states. During 2002, 87\% of all reported dengue cases occurred in the states located in the Southeast and Northeast macroregions of the country (23). This was an increase from the 1999-2001 period, when that proportion was around $80 \%$ (17). The Southeast and Northeast regions consist of the states located along the Atlantic coast of Brazil. Together, the two regions have $70.8 \%$ of the Brazilian population. Although Roraima is in the North region, the state has had the country's highest dengue incidence rates (cases per 10000 inhabitants) in recent years: 122.6 in 1999, 224.9 in 2000, and 164.2 in 2001 (17). In 2002, Roraima held the third highest dengue incidence values in Brazil (117.6 per 10 000), following Rio de Janeiro (177.5 per 10 000) and Pernambuco (152.0 per 10 000).

Boa Vista $\left(02^{\circ} 49^{\prime} 11^{\prime \prime} \mathrm{N}, 60^{\circ} 40^{\prime} 24^{\prime \prime} \mathrm{W}\right)$ has an area of $5687 \mathrm{~km}^{2}$ and is located on the Branco River. The predominant ecological environment in Boa Vista is savannah. The climate is tropical wet and dry, with an average temperature of $27.8^{\circ} \mathrm{C}$ (10-year average) (24) and very low intra-annual variability. Average yearly rainfall amounts to approximately $429 \mathrm{~mm}$ (4-year average) 
FIGURE 1. Brazil, state of Roraima, and city of Boa Vista
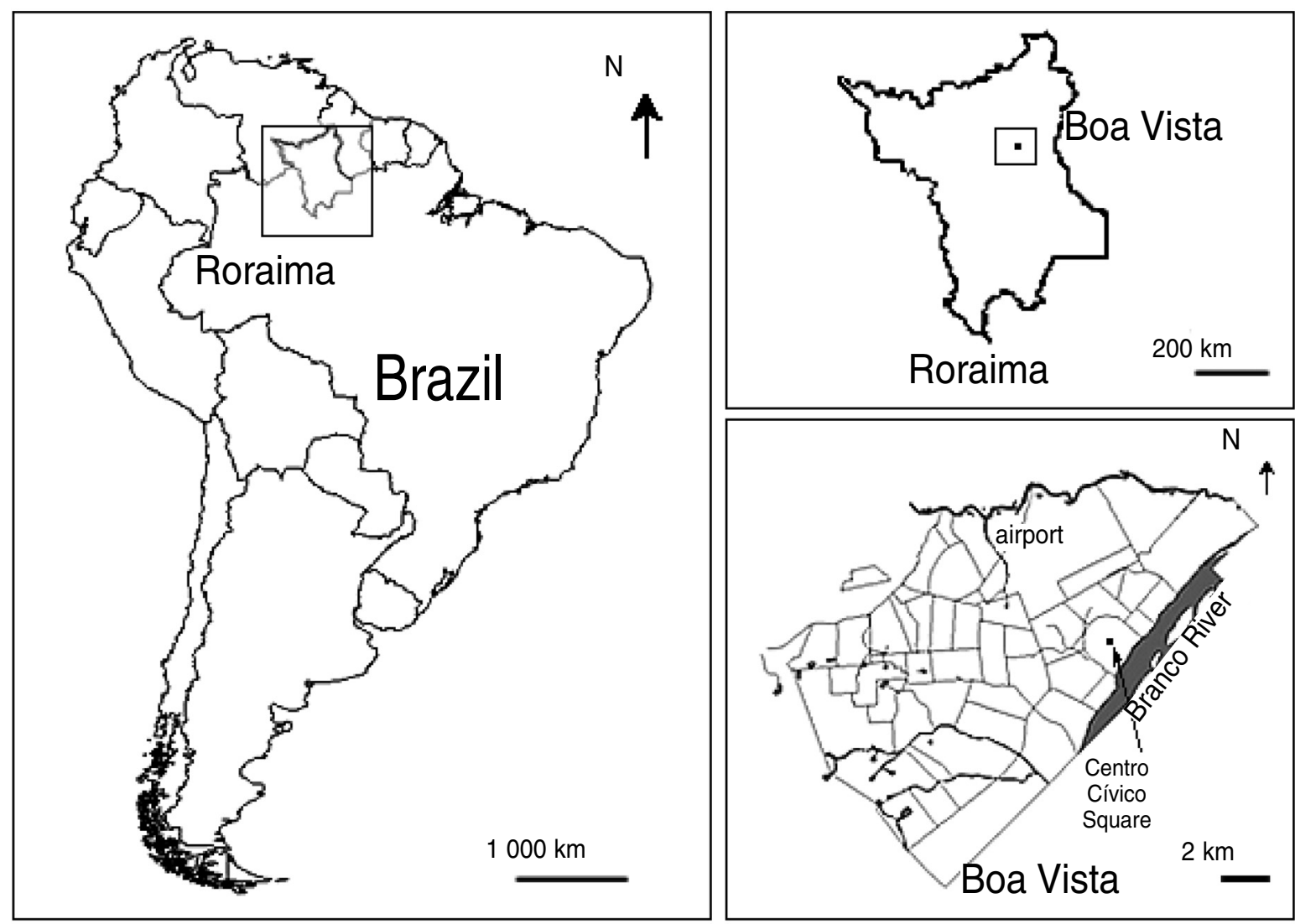

(25). Schmidt (25) described the regional climate as having two distinct seasons: (1) a rainy season, between April and November, with high rainfall indices during the months of June and July, and (2) a dry season, from December to March. A three-year study of Boa Vista showed a dry season between October and March and a wet season between April and September, with high rainfall indices especially in June and July (2). The north-south movement of the solar radiation belts over the year results in a seasonal variation of atmospheric pressure and wind for Boa Vista that is also typical of many tropical areas. As such, Boa Vista is impacted by cyclical rotations between the wet intertropical convergence zone (which brings convergent equatorial westerlies in the high-sun portion of the year) and the northern hemisphere subtropical anticyclone (with drier, easterly trade winds during the lowsun period) (26).

\section{Population and city characteristics}

The population and the landscape of the city of Boa Vista have been described previously (2). Briefly, Boa Vista has nearly 200000 individuals, with an average annual income of US\$ 714, according to data from the year 2000 (27). Many streams (igarapés) and rivers cross Boa Vista. As part of malaria vector control programs, most urban lakes were drained and filled. The main river is the Branco River, which flows past the city in a southwesterly direction.

For an Amazonian city, Boa Vista has an above-average quality of life. Housing conditions are fairly good, with around $90 \%$ of the residences having sanitary installations (although most of them are not linked to the sewage system), a connection to the city water system, and routine trash collection (27). Septic tanks are the most common method used to treat sewage. Throughout the city, houses usually lack inside and outside large water reservoirs (cisterns), thus indicating that water is fairly accessible. There are 4 general hospitals and 13 health units. The literacy rate in the city is $69 \%$. The neighborhoods of central and northeastern Boa Vista have higher average family income levels.

The residents of Boa Vista are concentrated around the city's central axis, where most dengue cases are also reported. Mosquito vector control includes house visits for infestation determination and breeding-place destruction, educational campaigns, and outdoor spraying of insecticides. The breeding places used by Aedes aegypti in Boa Vista are of many types. Poten- 
tial breeding places include car tires, ceramic tanks, plant vases, construction materials, car parts, glass and plastic bottles, aluminum soft drink containers, wells, water tanks (cisterns), pools, and natural containers. All of these potential breeding place are found in the peridomicile and its immediate surroundings (2).

\section{Dengue notifications}

Since 1996, compulsory notification by health practitioners has been required for patients reporting denguelike symptoms (high fever, headache, arthralgia, myalgia, and dizziness). However, only reports since 1999 have been collected as part of a comprehensive data collection system and reported daily to both the municipal and state health secretariats (the Secretaria Municipal de Saude and the Secretaria do Estado de Saúde de Roraima, respectively). Further, daily notification totals based on spontaneous individual reports appear to be heavily influenced by undercounting on weekends and holidays (2).

The number of dengue cases reported in the city of Boa Vista was 758 in 1999 (38.5 per 10000 inhabitants), 4031 in 2000 (204.5 per 10000 ), and 2962 in 2001 (150.3 per 10 000). Dengue affected both sexes in all ages during those years (2). Major risk areas for dengue transmission were located in a $10.5-\mathrm{km}$ central east-west horizontal axis from the Centro Cívico Square (Figure 1). During the study period the average premise infestation index was 1.25 for Boa Vista, and the Breteau index was 1.37 (2). (For this study, the premise or house index is the number of positive domiciles for immature forms of Ae. aegypti per 100 houses inspected, and the Breteau index is the number of containers positive for $A e$. aegypti immature forms per 100 houses inspected.) Neighborhoods located in the central axis displayed premise infestation and Breteau indices up to 13.73 (2).

Using the comprehensive daily unconfirmed dengue totals for Boa Vista for 1999-2001, 3-week-based daily running averages of reported dengue case numbers, hereafter referred to as "DCN," were calculated. Each day of the three-week running average changes by removing the oldest day of the 21-day period and adding on the next day. DCN were seen as superior to ordinary daily totals since great fluctuation in daily data brought on by day-of-the-week effect, holidays, and other unrelated "noise" may obscure real, longer-term relationships that exist between dengue and climate.

\section{Meteorological and hydroclimatic factors}

Meteorological data registered daily for the period September 1998 through December 2001 included daily rainfall $(\mathrm{mm})$, relative humidity $(\%)$, temperature $\left({ }^{\circ} \mathrm{C}\right)$, wind direction $\left({ }^{\circ}\right)$, wind speed $(\mathrm{m} / \mathrm{s})$, and atmospheric pressure $(\mathrm{kPa})$. Average daily values of the meteorological data were provided to us by the Boa Vista Air Force Base, which maintains data acquisition equipment in the airport area (Figure 1). June 1999 data were based on monthly averages because of incomplete data collection during that month. For temperature only, daily maximum and minimum values were provided to us. Average temperature, used in the water budgeting procedure outlined below, was calculated as the average of the maximum and minimum daily temperature. Wind direction and wind velocity were decomposed into the east-west and north-south components of the wind vector. Each day shows a value for each wind component, with days with strong southerly winds showing a relatively high positive north-south component, and days with strong westerly flow showing a relatively high positive east-west component. Wind speed was also evaluated separately. Precipitation, atmospheric pressure, and relative humidity were used in unaltered form. All daily weather measures were converted to three-week running averages similar to those used for DCN, resulting in the development of short-term climate measures.
Hydroclimatic factors were developed for Boa Vista by using the Thornthwaite-Mather climatic water budget (28-30). The climatic water budget methodology is a mass-balance technique that compares the climatic evaporative demand for water to incoming precipitation in order to reveal the many aspects of moisture relations for a location. In the process, soil moisture storages, losses, and gains are tracked. The procedure is ideal for evaluating dengue prevalence because it tracks the availability of the environmental energy and moisture that are critical to the dengue arbovirus and mosquito vector reproduction and survival. The Thornthwaite-Mather scheme is useful for developing a longterm hydroclimatology because the only required inputs are temperature and precipitation, which are routinely measured at weather stations. Inputs to our analysis of Boa Vista included daily total precipitation and daily average temperature, which was used to estimate potential evapotranspiration, using Thornthwaite's empirical formula (31). Factors describing the various hydroclimatic relations were then replicated using the WATBUG computer model (32). Because the focus in this application was on water storage within peridomestic containers in which Ae. aegypti breed, rather than within the soil matrix, the soil moisture retention curve was set to zero in order to simulate free evaporation from the containers (simple bucket model). Outdoor precipitation receipts may not heavily impact water levels in indoor containers. However, outdoor precipitation, temperature, and other climate indicators still may affect indoor temperature and humidity and thus indoor mosquito survival and behavior. Also, a high proportion of outdoor peridomestic containers will be at least partially impacted by the ambient atmosphere. This assures reasonable relevancy of the water budget model to the study.

Model outputs included potential evapotranspiration, actual evapotranspiration, container water storage, deficit, and surplus. Potential evapotranspiration reflects the climatic evaporative demand for water from the 
vegetation and soil of a closed, homogeneous cover of vegetation that never suffers from a lack of water (soil moisture at field capacity). Actual evapotranspiration shows the amount that actually does evaporate when conditions for potential evapotranspiration are not met. Container water storage indicates the depth of water stored in peridomestic containers, and it is calculated in the model as the balance of potential evapotranspiration, precipitation, and water-container holding capacity, assuming free evaporation of moisture. Deficit represents the amount by which actual evapotranspiration falls short of potential evapotranspiration. Surplus shows the additional amount of water available beyond maximum container water storage. Similar to the other climate variables, daily water-budget indicators were converted to daily short-term climate measures based on three-week running averages of daily values.

\section{Statistical analysis}

We used Pearson product-moment correlation analysis to investigate individual relationships between climate measures and the number of dengue cases for Boa Vista. Our study procedure was similar to the one that Schreiber used for the city of San Juan, Puerto Rico. ${ }^{5}$ In that study, DCN were related to 3-week running averages of thermal and hydroclimatic factors. DCN were lagged behind the climate measures by 0 to 25 weeks. In order to account for differences in relationships between DCN and climate over the year, the statistical analysis performed for the San Juan analysis done by Schreiber was also broken into three periods: early-year (January-April), mid-year (May-August), and late-year (September-December). The same procedure was applied to Boa Vista, but incorporating additional climate measures of atmospheric pressure, wind, and humidity.

\footnotetext{
Schreiber KV. An improved hydroclimatic approach to assessment of dengue. Part I: seasonal assessment for San Juan, Puerto Rico. In preparation.
}

To expand beyond simple correlation analysis of individual climate factors and dengue, impacts of combinations of weather factors were explored in two-sample $t$ tests. While individual variables may show little relationship with dengue, otherwise undetectable relationships become apparent when subject to multivariate analysis. Hence, combinations of three climate variables were sought that best discriminated between low DCN and high DCN. Three variables were chosen to provide maximal information for discrimination, while avoiding the small sample size that occurs for larger numbers of variables. The choice of variables was guided with the "all-possible regressions" procedure (SAS software PROC RSQUARE) (SAS Institute Inc., Cary, North Carolina, United States of America). That linear multiple-regression technique is used to identify particular combinations of variables that result in the greatest explained variance of the dependent variable. The technique is superior to stepwise procedures in that every combination of the regressors is evaluated. We selected the variables based only on their contribution to the total variance explained by the model, rather than on any notions of causality.

For our purposes, the three variables selected by the all-regression procedure were used to discriminate groups for comparison in two-sample $t$ tests. When a particular day met the criterion of having values of all the selected climate variables that were above or below (as appropriate) the average for those climate variables, the DCN was placed in a test sample. For example, for the early-year period, higher DCN were associated with higher relative humidity 10 weeks prior to DCN, lower minimum temperature 3 weeks prior to DCN, and lower wind speed 12 weeks prior to DCN. When the exact opposite climatic condition occurred, the DCN value was placed in a second test sample. The resulting test samples of DCN were then evaluated for statistically significant differences in a two-sample $t$ test. Many other combinations of variables are likely to result in statistically different high or low DCN, but the combination pre- sented in this work is associated with the highest explained variance of any three variables.

\section{RESULTS}

\section{Statistical analysis of dengue and hydroclimatic and meteorological factors}

Application of 3-week running averages to variables, together with experimentation with varying lag periods between dengue and climate, resulted in stronger correlations among variables than previously observed using unaveraged meteorological variables (Table 1 shows correlations between thermal/hydroclimatic variables and DCN January through April, Table 2 shows correlations for May through August, and Table 3 presents correlations for September through December). The strength of the individual correlations ranged from weak to moderate. The strength of the correlations varied according to the period of the year, the particular variable, and the lag period. During the early-year period (January-April), minimum temperature, atmospheric pressure, wind speed, and relative humidity presented the strongest individual relationships with dengue (for particular lags with highest correlations) (Table 1). For the mid-year period (May-August), wind variables, container water storage, atmospheric pressure, and actual evapotranspiration showed the best correlations (Table 2). Stronger correlations in the late-year period (SeptemberDecember) were similar to those for the mid-year period, except they excluded atmospheric pressure and included minimum temperature (Table 3). Comparisons of the times series of DCN with the individual climate measures most associated with DCN appear in Figure 2. The degree of temporal correspondences between DCN and climate variables varies from year to year and according to climatic variable.

For each variable, the lag period presenting the strongest relationship with DCN similarly varied according to season. While the strongest early- 
TABLE 1. Correlations between thermal/hydroclimatic variables and the early-year (January-April) time series of daily running averages of number of reported dengue cases (DCN) in Boa Vista, Roraima, Brazil, September 1998-December 2001a

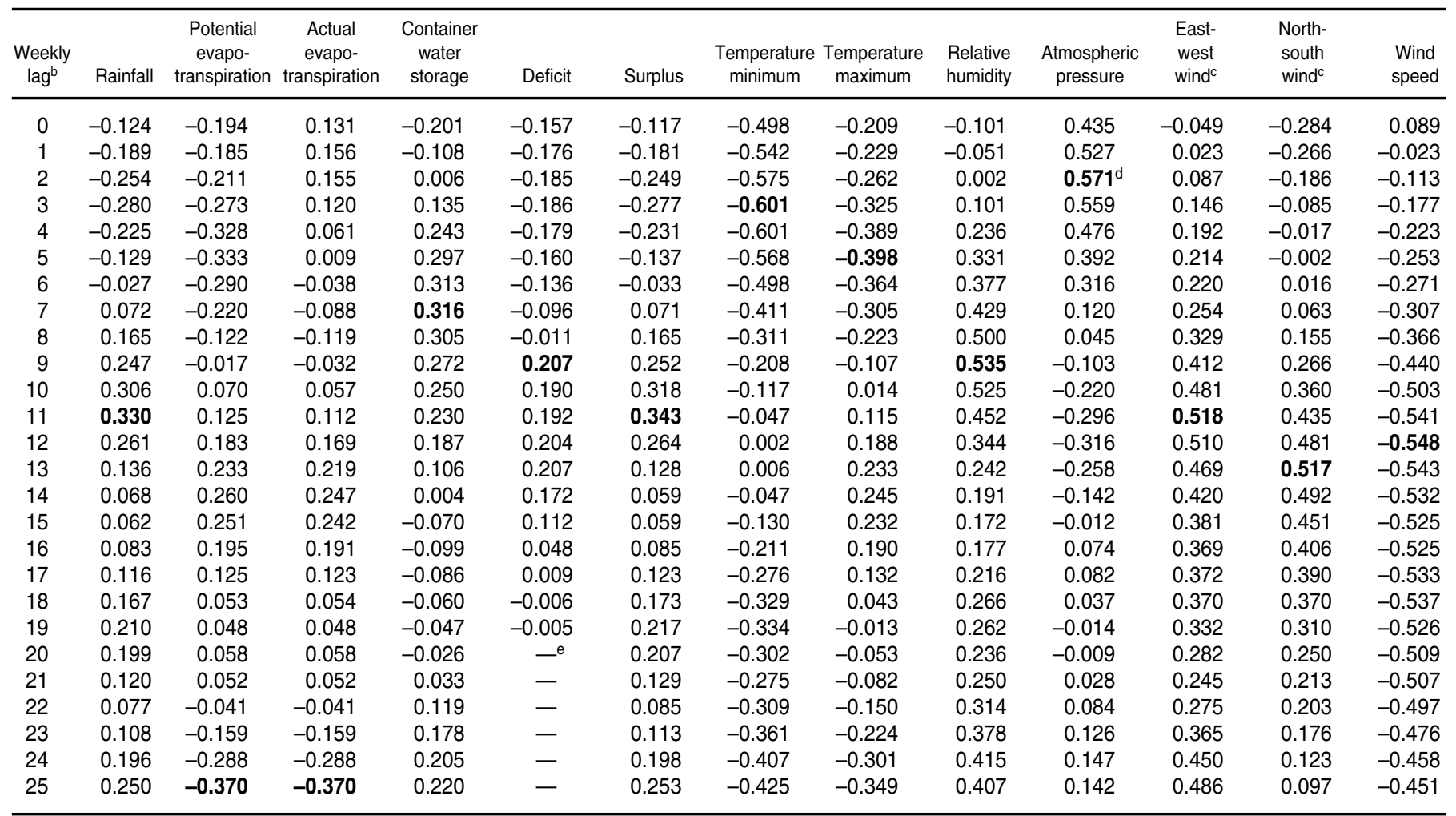

a Twenty-six lag variables were developed for each meteorological variable, based on the lag period between number of dengue cases and climate ( 0 to 25 weeks).

${ }^{\mathrm{b}}$ Number of weeks the climate variable preceded DCN.

${ }^{c}$ Components of the wind vector.

d The bolded values represent the highest lag correlation for the meteorological variable.

e The "-" symbol indicates insufficient values for the variable for the time period.

year relationships were often found when DCN lagged climate indicators by 3 to 11 weeks (with a lag of $23-25$ weeks also being important), common lags for the mid-year period were 13 to 25 weeks. Lag periods for the late-year period were much more variable, but centered around 13 to 15 weeks.

The previously described twosample $t$ test showed statistically significant differences between separate DCN samples classified according to the seasonal climate criterion (i.e., test condition) (Table 4). Climatic variables selected by the all-regressions procedure for use in the $t$ test preceded dengue observations by 2 to 25 weeks. From the set of climatic variables evaluated in the all-regression procedure, atmospheric pressure, wind, and humidity variables were frequently among the selected three variables that presented the highest explained DCN variance (Table 4). There was greater statistical significance for $t$ tests using samples based on three discriminating climate variables than there was for $t$ tests using samples based on two factors.

\section{DISCUSSION}

Investigations exploring stochastic weather/disease relationships differ widely in the importance attributed to climate in arthropod-borne disease ecology. Monthly dengue incidence that lagged three months behind temperature was statistically significant in Puerto Rico, but the variable was not seen as an absolute determinant (33). Abnormal increases of maximum tem- perature and rainfall had no positive association with malaria epidemics in Ethiopia, but abnormally high minimum temperature in the preceding three months showed significant relationships (34). In the cities of Kericho, Kenya, and Bangkok, Thailand, no significant variation in temperature and rainfall beyond an annual cycle were seen, suggesting that oscillations in dengue and malaria are inherent within the host-parasite population dynamics, rather than driven by interannual climate variation (35). However, in San Juan, Puerto Rico, a wide variety of thermal and hydroclimatic variables were significantly associated with the number of dengue cases, and they produced seasonal climate-based models that could account for $75 \%-$ $81 \%$ of the dengue variance, according 
TABLE 2. Correlations between thermal/hydroclimatic variables and the mid-year (May-August) time series of daily running averages of number of reported dengue cases (DCN) in Boa Vista, Roraima, Brazil, September 1998-December 2001 ${ }^{\text {a }}$

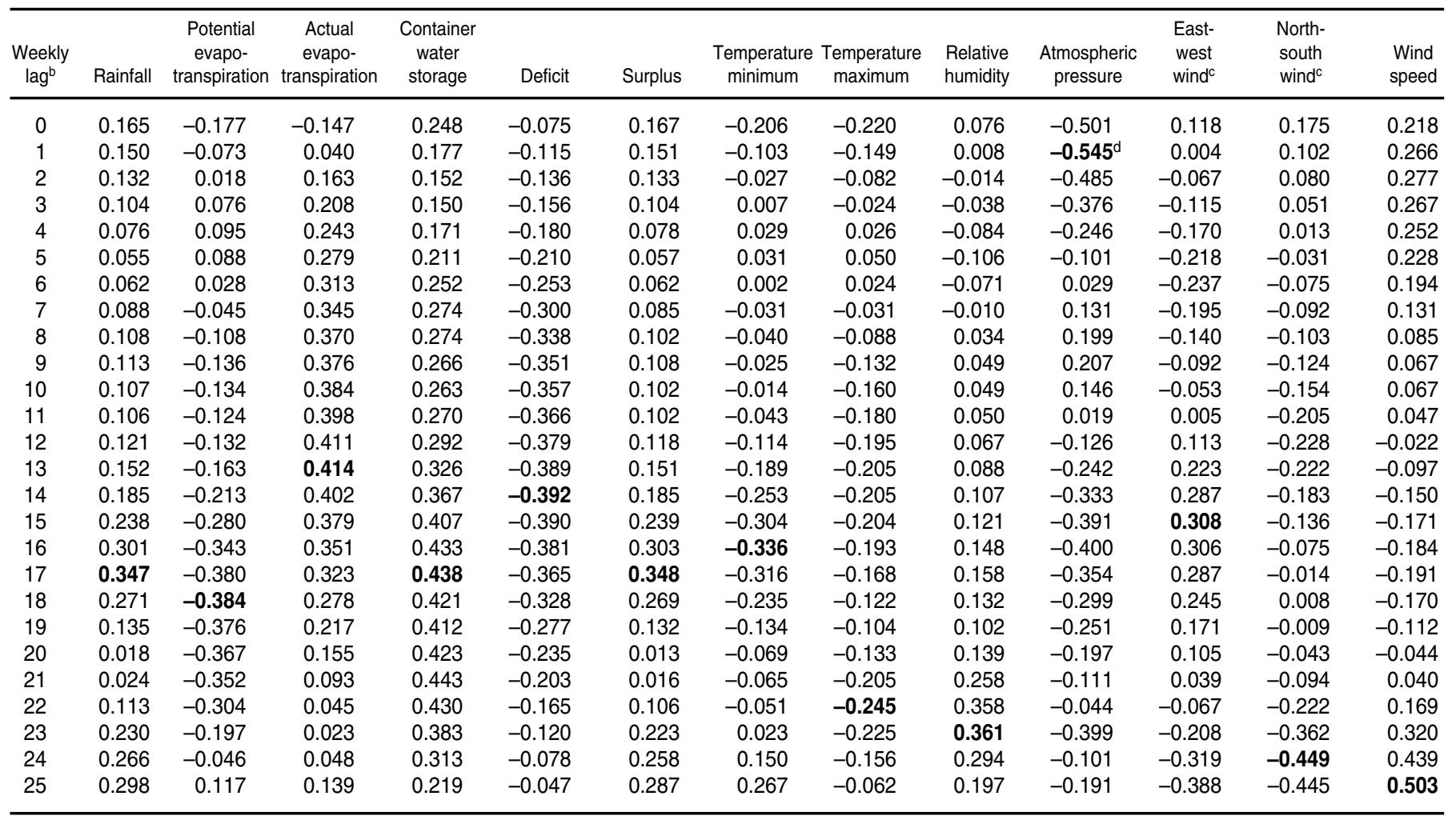

a Twenty-six lag variables were developed for each meteorological variable, based on the lag period between number of dengue cases and climate $(0$ to 25 weeks).

${ }^{b}$ Number of weeks the climate variable preceded DCN.

${ }^{c}$ Components of the wind vector.

${ }^{\mathrm{d}}$ Bolded values represent the highest lag correlation for the meteorological variable.

to the paper mentioned earlier that is being prepared by KV Schreiber.

Other recent studies have emphasized the role of intrinsic population dynamics (e.g., pathogens, hosts, and vectors) over climatic drivers in the length of interepidemic periods (35, 36). For example, using spectral density analysis, Hay et al. (35) failed to find a relationship between the periodicity of monthly average temperature/ precipitation with the length of interepidemic periods for dengue in Bangkok. However, the Hay et al. study (35) did not rule out the impact of short-term climate on other temporal aspects (e.g., magnitude) of the dengue time series. Additionally, other commonly available weather elements outside of average monthly temperature and precipitation were not evaluated. Nonperiodic climate events were also not analyzed. Population and study area characteristics differ substantially between Boa Vista and Bangkok, possibly influencing the relative importance of intrinsic and extrinsic (e.g., climate) controllers of dengue incidence. In some instances, extrinsic and intrinsic factors might interplay in such a complex net of interrelations so as to become indistinguishable. Another study for Bangkok (37) found that the timing of dengue epidemics was based on a combination of intrinsic disease factors and climate variations driven by El Niño Southern Oscillation events.

In addition to different geographical, temporal, and epidemiological factors, methodological considerations are likely to account for some of the observed differences in results of studies of weather influences on mosquitotransmitted disease. The mix of procedures used in this study of Boa Vista (meteorological data averaging, use of lengthy temporal lag periods, use of seasonal data) has been important in detecting underlying climate/dengue relationships that could not be seen previously.

This study of Boa Vista suggests that antecedent climate conditions have a differential impact on dengue over the course of the year. Minimum temperature and relative humidity are important in the early-year period. However, those two factors are much less significant in the mid-year period, and they change again for the lateyear period. These part-year correlations were significantly higher in 
TABLE 3. Correlations between thermal/hydroclimatic variables and the late-year (September-December) time series of daily running averages of number of reported dengue cases (DCN) in Boa Vista, Roraima, Brazil, September 1998-December 2001

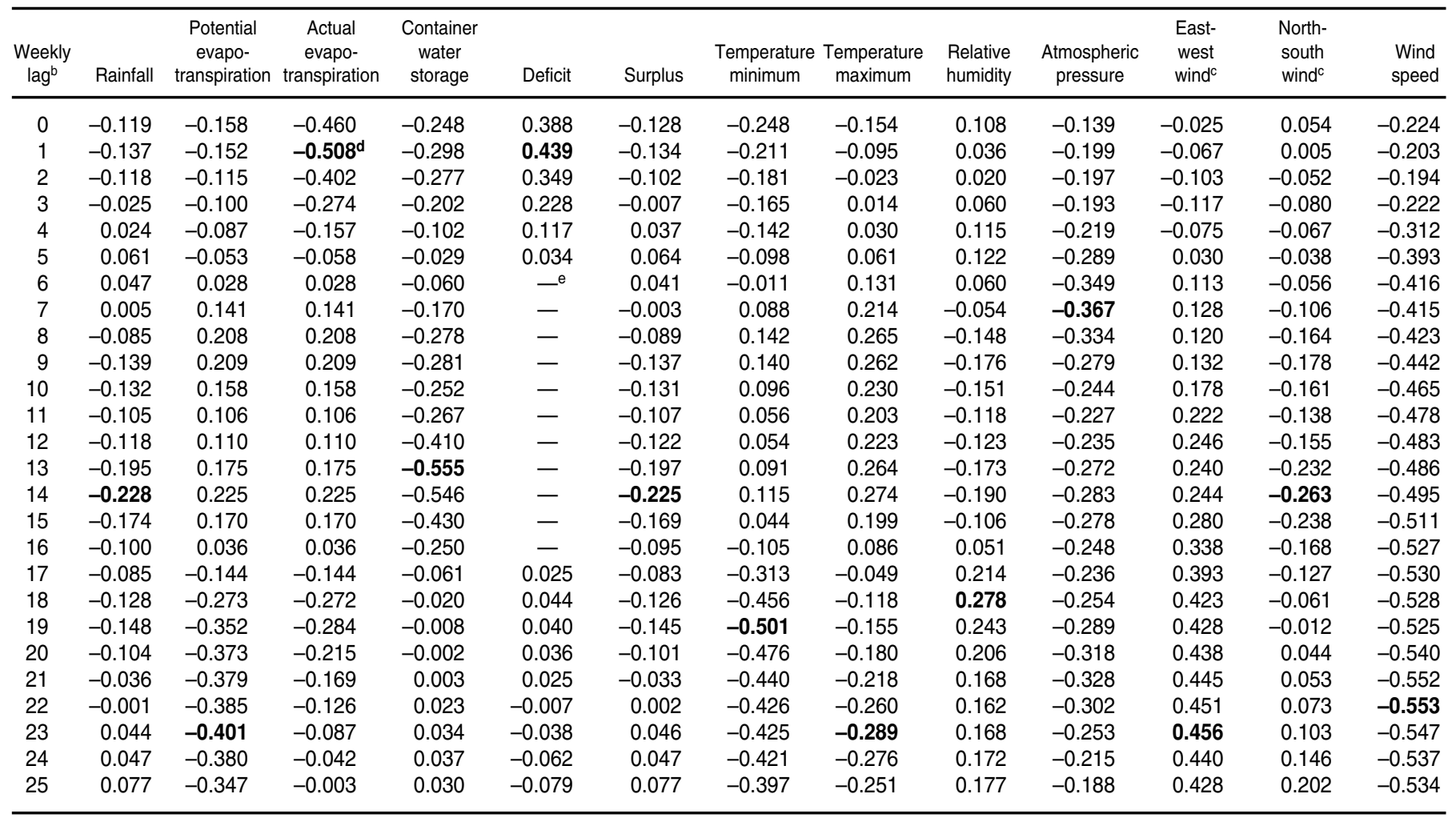

a Twenty-six lag variables were developed for each meteorological variable, based on the lag period between number of dengue cases and climate ( 0 to 25 weeks).

${ }^{b}$ Number of weeks the climate variable preceded DCN.

c Components of the wind vector.

${ }^{d}$ The bolded values represent the highest lag correlation for the meteorological variable.

e The "-" symbol indicates insufficient values for the variable for the time period.

magnitude than were the full-year correlations. The higher correlations were observed because periods over which particular variables were less influential were not evaluated in combination with periods yielding greater explanatory power. Short-term climate and vector biology/behavior may vary from one season to another. Therefore, particular climate conditions promoting dengue in one portion of the year may either be nonexistent or irrelevant during other portions of the year. For example, in Boa Vista, running averages of relative humidity above $80 \%$ occur only from May to August, and southerly and westerly winds rarely occur outside that same time period. Limiting analysis to separate portions of the year that have distinctive antecedent climate regimes makes it possible to determine the impact of periodspecific elements of climate. Our results for Boa Vista illustrate the importance of focusing analysis on short, relevant time periods.

The strength of correlations for humidity, atmospheric pressure, and wind variables at particular times of the year exceeded those of more commonly evaluated climate variables, including thermal and hydroclimatic indicators. This calls attention to the need to consider a full array of climate drivers in vector-borne epidemiological research, including those factors less commonly evaluated and/or measured. For example, dew or other heavy condensation may result in incomplete eclosion of unconditioned Ae. aegypti eggs. Subsequent desicca- tion of exposed, unsubmerged larvae may then result in high larval mortality (38) The incidence of dengue is likely to be affected by the duration of moisture deficit; rainfall intensity, duration, and timing; light intensity; temperature variability; and a variety of climatic anomalies.

The role of wind factors and atmospheric pressure on dengue has been less reported in the scientific literature. Reiter (39) notes that wind is key in flight-capable arthropod migration and dispersal, and may be responsible for the introduction of an arbovirus to a nonendemic area, or a sudden reappearance of an arbovirus after a period of absence. Traveling storm systems offer a related means of transport. North American birds and insects have been commonly found along the 
FIGURE 2. Three-week running averages of reported daily numbers of dengue cases (DCN) and the most highly correlated climate variables for the early-year period (January-April), mid-year period (May-August), and the late-year period (September-December) in Boa Vista, Roraima, Brazil, September 1998-December 2001 ${ }^{\text {a }}$
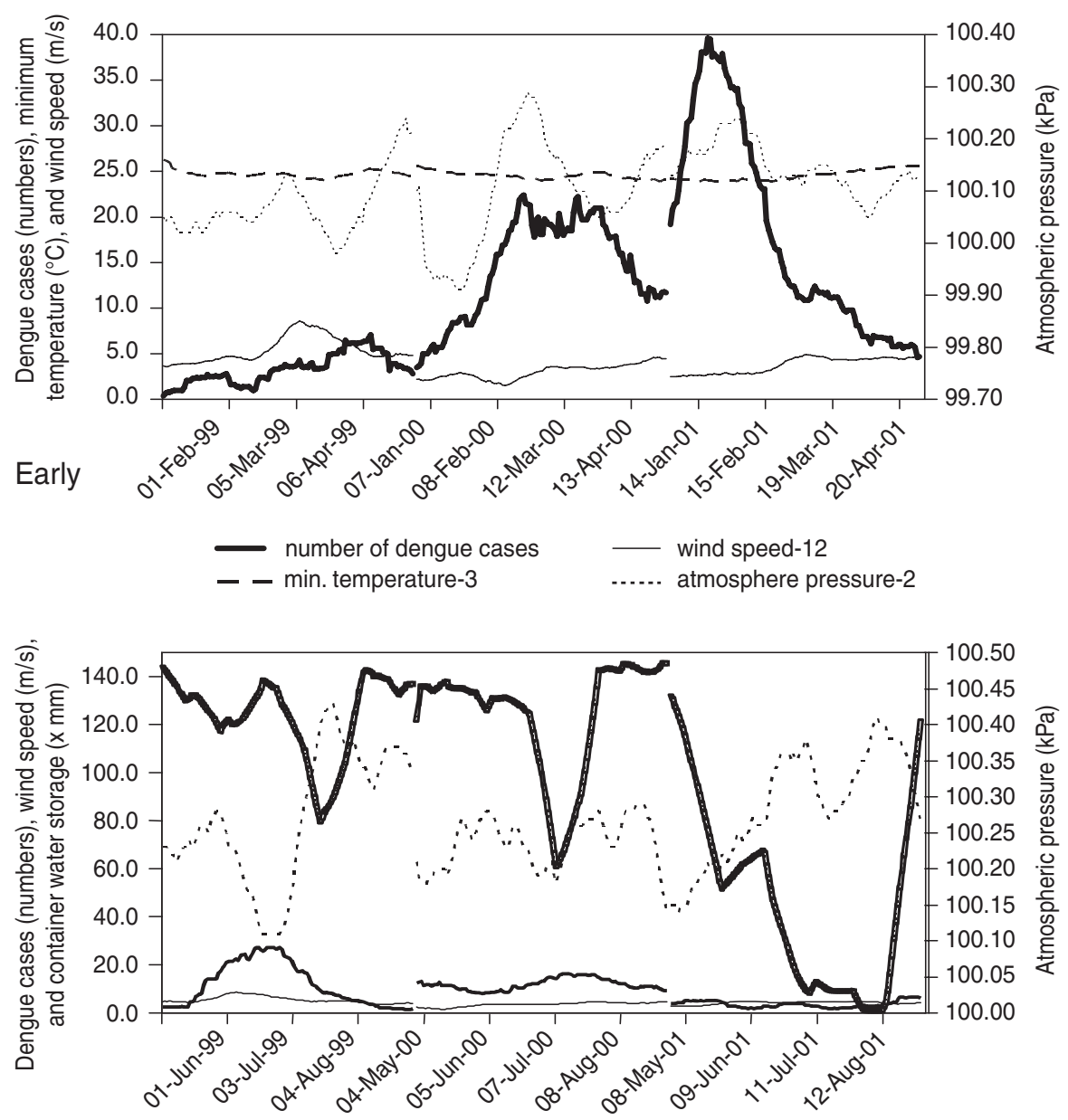

Mid
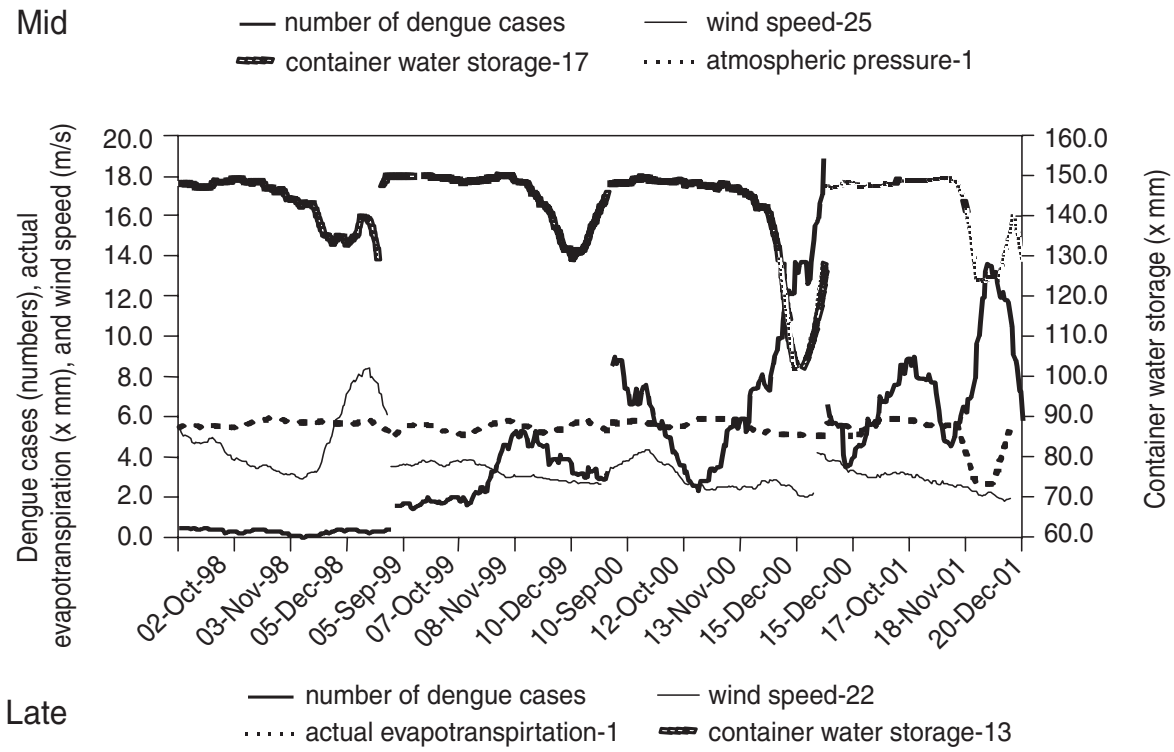

a The variables represented in the left axes have the same scale. Twenty-six lag variables were developed for each meteorological variable, based on the lag period between dengue and cli-
mate ( 0 to 25 weeks). The number given in the legend after the variable represents the number of weeks the climate variable preceded the dengue observation. 
TABLE 4. Two-sample, two-tailed $t$ test (assuming unequal sample variances) comparing daily running averages of number of reported dengue cases (DCN) samples discriminated by the three climatic variables explaining the highest DCN variance (test condition), Boa Vista, Roraima, Brazil, September 1998-December 2001

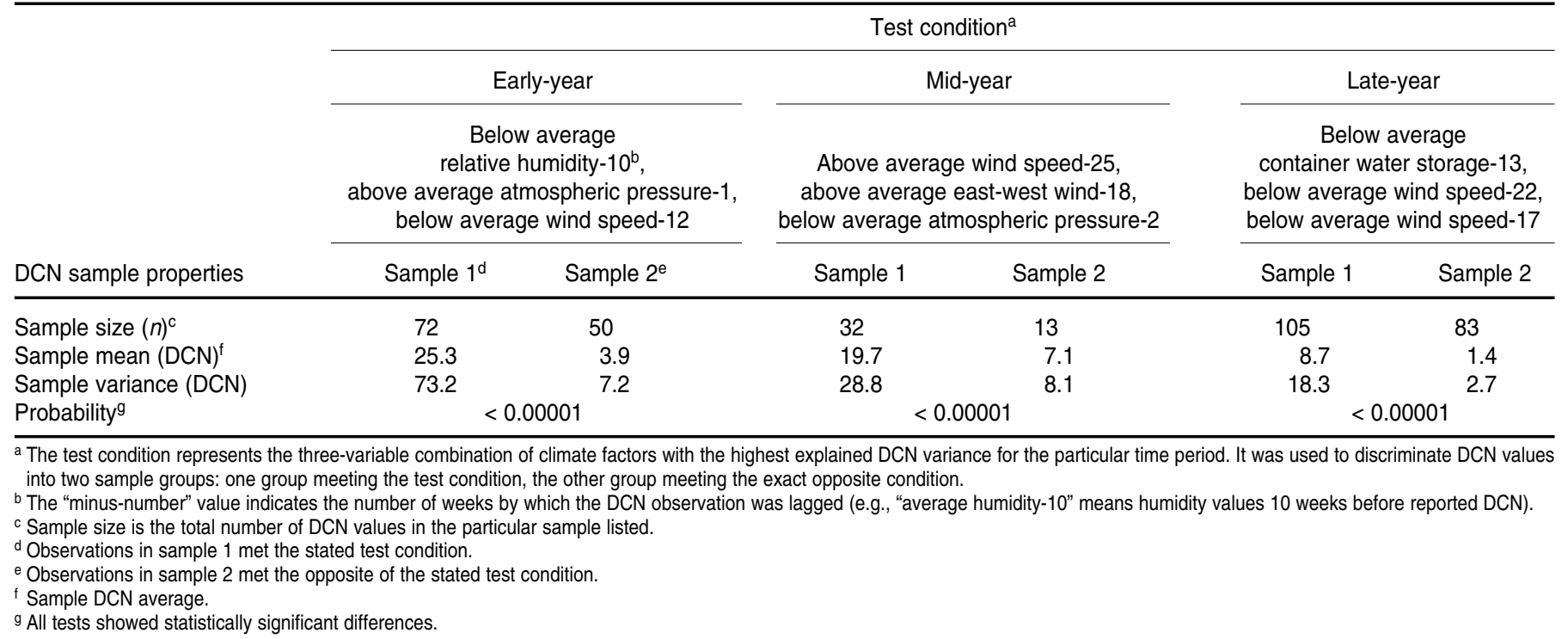

coasts of England and Ireland after having been carried in strong storms across the Atlantic (40). While air movement may play an important role in the transport of infected vectors, wind may also reduce mosquito flying activity and contact with humans (41). Kennedy (42) showed wind speeds over $150 \mathrm{~cm} / \mathrm{sec}$ caused female $A e$. aegypti in a wind tunnel to alight, and they were unable to resume flight at those wind speeds. Thus it appears that even wind speeds that are light to moderate may immediately reduce mosquito activity and dengue transmission. However, if transport of infected vectors to an area raises the proportion of infected mosquitoes, light to moderate wind speeds may eventually increase dengue incidence.

In part, the weak correlation of dengue with some climate variables found in our Boa Vista study and other studies might result from the fact that Ae. aegypti is a domesticated vector. With its synanthropic habits, Ae. aegypti can find shelter in human dwellings that provide small fluctuations in temperature and humidity, protection from wind and rain, abundant breeding locations, and plentiful blood sources $(18,19)$.
Individual variables can shed valuable light on relationships between climate and disease. However, in the environment, numerous features of climate simultaneously impact dengue transmission. The full effect of climate can only be understood by simultaneously evaluating the multiple inherent impacts that the climate system has on dengue. This study of Boa Vista is an initial effort at such a multifaceted approach. The climate variables providing the highest explanatory power for DCN preceded dengue incidence by two or more weeks. Therefore, the technique may be used to predict periods of significantly higher dengue levels. This would enhance control strategies by placing them in the right time and space. To extend the tool's prediction period, reevaluation of the discriminating factors could be performed using only those climate variables antecedent to dengue by the desired time interval for prediction. The success of this procedure suggests a multivariate approach to the evaluation of climate and dengue (e.g., multiple regression) holds promise for uncovering stronger relationships than found for individual correlation analysis. Studies based on a multivariate ap- proach in diverse epidemiological conditions may thus lead to a better understanding of the dengue ecology.

\section{CONCLUSIONS}

Among the multiplicity of interacting factors driving vector disease ecology, climate plays an integral role. Among the other factors that affect dengue transmission rates are virus type and immunity, prevalence of mosquito breeding sites, densities and sizes of human and mosquito populations, and proportion of infected mosquitoes and humans. Our study in Boa Vista suggests that short-term climate variations, especially when considered in a multivariate fashion, are associated with dengue incidence in Boa Vista, Brazil.

The study reaches four other key conclusions for Boa Vista. First, shortterm climate measures produced by averaging daily meteorological data show stronger relationships with DCN than do daily meteorological data alone. Second, significant relationships between climate and DCN occur sometimes over lengthy lag intervals (up to at least 25 weeks). Third, antecedent 
climate conditions have differential associations with DCN over the course of the year. Therefore, climate/dengue analyses should be focused on specific seasons or months of the year. Finally, wind, atmospheric pressure, humidity variables, minimum temperature, and container water storage for particular times of the year hold particularly strong associations with dengue.

Because of its potential to identify periods of elevated dengue incidence, climate-based temporal stochastic analyses should be integrated into local programs to control vector-transmitted diseases. These analyses help to initiate early interventions, plan for the prevention of disease outbreaks and their spread, and assess the success of strategies to control dengue. Many of the variables that we studied in Boa Vista showed only mild individual correlations with DCN. Nevertheless, collective analysis of climatic terms is likely to substantially improve explained variance. Our ability to identify combinations of climatic factors that discriminate periods of high DCN and of low DCN suggests that success in developing a climate-based model for dengue prediction is likely, and that it should be pursued.
Acknowledgements. This work was supported by the Brazilian Council for Science and Development-CNPq (521176/98-0), the Oswaldo Cruz Institute-FIOCRUZ, and the Roraima Federal University-UFRR. Grateful thanks are offered to the Fundação Nacional de Saúde-FUNASA, Laboratório Central-LACEN, Instituto Brasileiro de Geografia e Estatística-IBGE-Roraima, Secretaria do Estado de Saúde de Roraima-SESAU, Secretaria Municipal de Saúde-SEMSA, Prefeitura de Boa Vista, and the three anonymous peer reviewers, who substantially improved the quality of the manuscript.

\section{REFERENCES}

1. Reiter P. Climate change and mosquito-borne disease. Environ Health Perspect. 2001;109 (suppl 1):141-52.

2. Rosa-Freitas MG, Tsouris P, Sibajev A, SouzaWeimann ET, Marques AU, Ferreira RL, et al. Exploratory temporal and spatial distribution analysis of dengue notifications in Boa Vista, Roraima, Brazilian Amazon, 1999-2001. Dengue Bull. 2003;27:63-80.

3. Ram S, Khurana S, Kaushal V, Gupta R, Khurana SB. Incidence of dengue fever in relation to climatic factors in Ludhiana, Punjab. Indian J Med Res. 1998;108(10):128-33.

4. Barbazan P, Yoksan S, Gonzalez JP. Dengue hemorrhagic fever epidemiology in Thailand: description and forecasting of epidemics. Microbes Infect. 2002;4(7):699-705.

5. Schreiber KV. An investigation of relationships between climate and dengue using a water budgeting technique. Int J Biometeorol. 2001;45(2):81-9.

6. Gagnon AS, Bush ABG, Smoyer-Tomic KE. Dengue epidemics and the El Niño Southern Oscillation. Clim Res. 2001;19(1):35-43.

7. Bouma MJ. Climate change and tropical disease: methodological problems and amendments to demonstrate effects of temperature on the epidemiology of malaria. A new perspective on the highland epidemics in Madagascar, 1972-89. Trans R Soc Trop Med Hyg. 2003;97(2):133-9.

8. De La Rocque S, Michel JF, De Wispeleare G, Cuisance D. De nouveaux outils pour l'étude des trypanosomoses animales en zone soudanienne: modélisation de paysages épidémiologiquement dangereux par télédétection et systèmes d'information géographique. Parasite. 2001;8:171-95.

9. Hales S, de Wet N, Maindonald J, Woodward A. Potential effect of population and climate changes on global distribution of dengue (9336):830-4. fever: an empirical model. Lancet. 2002;360

10. Watts DM, Burke DS, Harrison BA, Whitmire RE, Nisalak A. Effect of temperature on the vector efficiency of Aedes aegypti for dengue 2 virus. Am J Trop Med Hyg. 1987;36(1): 143-52.

11. Macdonald WW. Aedes aegypti in Malaya II. Larval and adult biology. Ann Trop Med Parasitol. 1956;50(4):300-414.

12. Rueda LM, Patel KJ, Axtell RC, Stinner RE. Temperature-dependent development and survival rates of Culex quinquefasciatus and Aedes aegypti (Diptera: Culicidae). J Med Entomol. 1990;27(5):892-8.

13. Focks D, Haile D, Daniels E, Mount G. Dynamic life table models for Aedes aegypti (Diptera: Culicidae): analysis of the literature and model development. J Med Entomol. 1993;30(6):1003-17.

14. Tun-Lin W, Burkot TR, Kay BH. Effects of temperature and larval diet on development rates and survival of the dengue vector Aedes aegypti in north Queensland, Australia. Med Vet Entomol. 2000;14(1):31-7.

15. Schoof HF. Mating, resting habits, and dispersal of Aedes aegypti. Bull World Health Organ. 1967:36(4):600-1.

16. Canyon DV, Hii JLK, Müller R. Adaptation of Aedes aegypti (Diptera: Culicidae) oviposition behavior in response to humidity and diet. J Insect Physiol. 1999;45(10):959-64.

17. Brasil, Fundação Nacional de Saúde, Sistema de Informação de Vigilância Epidemiológica Notificação de casos. Available from: http:/ / www.sis.funasa.gov.br [Web site]. Accessed 2 April 2004.

18. Souza-Santos R. Fatores associados à ocorrência de formas imaturas de Aedes aegypti na Ilha do Governador, Rio de Janeiro, Brasil. Rev Soc Bras Med Trop. 1999;32(4):373-82.
19. Kuno G. Review of the factors modulating dengue transmission. Epidemiol Rev. 1995;17 (2):321-35.

20. Travassos da Rosa APA, Rocha JM, Silva OV, Lins ZC. Surto de dengue em Boa Vista, Território de Roraima, Brasil. Bol Epidemiol. 1982;14(9):93-101.

21. Osanai $\mathrm{CH}$, Travassos da Rosa APA, Tang AT, Amaral RS, Passos AC, Tauil PL. Surto de dengue em Boa Vista, Roraima. Rev Inst Med Trop Sao Paulo. 1983;25(1):53-4

22. Vasconcelos PFC, Travassos-da-Rosa APA, Pinheiro FP, Rodrigues SG, Rosa EST, Cruz $\mathrm{ACR}$, et al. Aedes aegypti, dengue and reurbanization of yellow fever in Brazil and other South American countries-past and present situation and future perspectives. Dengue Bull. 1999;23:1-6.

23. Instituto Brasileiro de Geografia e Estatística. Mapas interativos. Available from: http:// mapas.ibge.gov.br/divisao/viewer.htm [Web site]. Accessed 14 April 2004.

24. United States of America, National Aeronautics and Space Administration. Surface meteorology and solar energy. Available from http://eosweb.larc.nasa.gov [Web site]. Accessed 2 February 2005.

25. Schmidt JCJ. O clima da Amazônia. Rev Bras Geogr. 1942;4(3):465-500

26. Trewartha GT, Horn LH. An introduction to climate. 5th ed. New York: McGraw-Hill; 1980

27. Instituto Brasileiro de Geografia e Estatística. Estados@. Available from: http://www.ibge. gov.br/estadosat/ [Web site]. Accessed 14 April 2004.

28. Thornthwaite CW, Mather JR. The water balance. Pub Clim. 1955;8(1):1-104.

29. Thornthwaite CW, Mather JR. Instructions and tables for computing potential evapotranspiration and the water balance. Pub Clim. 1957;10(3):181-311. 
30. Mather JR. The climatic water budget in environmental analysis. Lexington: Heath; 1978.

31. Thornthwaite CW. An approach toward a rational classification of climate. Geogr Rev. 1948;38:55-94.

32. Willmott CJ. WATBUG: a FORTRAN IV algorithm for calculating the climatic water budget. Pub Clim.1977;30(2):1-55.

33. Keating J. An investigation into the cyclical incidence of dengue fever. Soc Sci Med. 2001;53 (12):1587-97.

34. Abeku TA, van Oortmarssen GJ, Borsboom G, de Vlas SJ, Habbema JD. Spatial and temporal variations of malaria epidemic risk in Ethiopia: factors involved and implications. Acta Trop. 2003;87(3):331-40.

35. Hay SI, Myers MF, Burke DS, Vaughn DW, Endy T, Ananda N, et al. Etiology of interepi- demic periods of mosquito-borne disease. Proc Natl Acad Sci U S A. 2000; 97(16): 9335-9.

36. Cummings DA, Irizarry RA, Huang NE, Endy TP, Nisalak A, Ungchusak K, et al. Travelling waves in the occurrence of dengue haemorrhagic fever in Thailand. Nature. 2004;427 (6972):344-7.

37. Cazelles B, Chavez M, McMichael AJ, Hales S Nonstationary influence of El Niño on the synchronous dengue epidemics in Thailand. PLoS Med. 2005;2(4):313-8.

38. Christophers SR. Aedes aegypti (L.), the yellow fever mosquito: its life history, bionomics and structure. Cambridge: Cambridge University Press; 1960.

39. Reiter P. Weather, vector biology and arboviral recrudescence. In: Monath TP, ed. The ar- boviruses. Volume I: Epidemiology and ecology. Boca Raton: CRC; 1988. Pp 245-55.

40. Curtis H. Biology. 3rd ed. New York: Worth; 1979

41. Hoffmann EJ, Miller JR. Reduction of mosquito (Diptera: Culicidae) attacks on a human subject by combination of wind and vaporphase DEET repellent. J Med Entomol. 2002; 39(6):935-8.

42. Kennedy JS. The visual response of flying mosquitoes. Proc Zool Soc London (A). 1939: 109:221-42.

Manuscript received 19 July 2005. Revised version accepted for publication 5 May 2006.

RESUMEN Objetivos. El dengue se ha convertido en la enfermedad endémica más importante de Brasil. El estado amazónico de Roraima presenta una de las tasas de incidencia de dengue más elevadas de ese país. El objetivo del presente estudio fue determinar si existen relaciones temporales significativas entre el número de casos informados de dengue y las mediciones climáticas a corto plazo en la ciudad de Boa Vista, capital de Roraima. De comprobarse esa relación, existiría la posibilidad de predecir el número de casos de dengue a partir de las condiciones climáticas antecedentes, lo que contribuiría a desarrollar un sistema de aviso temprano de dengue basado en las mediciones climáticas en Boa Vista.

Métodos. Se calcularon coeficientes de correlación momento-producto de Pearson estacionales entre los promedios deslizantes del número informado de casos de dengue en lapsos de tres semanas entre septiembre de 1998 y diciembre de 2001 y los valores de algunas variables meteorológicas seleccionadas (temperatura, precipitaciones diarias, velocidad y dirección del viento, presión atmosférica y humedad relativa) hasta 25 semanas previas. Se aplicó la prueba de la $t$ para dos muestras para comprobar la significación estadística de las diferencias entre las muestras de casos diarios de dengue con valores por encima del promedio y las muestras diarias con valores por debajo del promedio para las combinaciones de tres variables meteorológicas. Estas combinaciones multifactoriales consistían en tres mediciones climáticas que juntas explicaran la mayor parte de la varianza en el número de casos de dengue para una estación dada.

Resultados. La robustez de las correlaciones de las medias individuales fue débil o moderada. Las correlaciones difirieron según el período del año, la variable climática en cuestión y el período transcurrido entre el momento en que se midió el indicador y cuando se notificaron los casos de dengue. La correlación estacional mostró una relación mucho más fuerte que la correlación diaria durante todo el año encontrada en estudios anteriores. La prueba de la $t$ para dos muestras aplicada a combinaciones meteorológicas con múltiples variables de los valores de presión atmosférica, viento y humedad mostraron diferencias significativas en cuanto al número de casos de dengue informados.

Conclusiones. Las relaciones entre el clima y el dengue se pueden analizar mejor en períodos de tiempo cortos y pertinentes. Los análisis estocásticos temporales basados en múltiples variables climáticas tienen la posibilidad de identificar períodos de elevada incidencia de dengue, por lo que se deben incorporar a los programas locales de control de vectores transmisores de enfermedades.

Palavras clave Dengue, brotes de enfermedades, Aedes, clima, tiempo (meteorología), modelos biológicos, predicción, Brasil. 